FLIGHT TO THE FRINGES:

AN EMPIRICAL STUDY OF OFFICE DECENTRALIZATION IN ATLANTA, GEORGIA

\author{
Fred A. Tarpley, Jr., Lawrence S. Davidson, and David D. Clark*
}

Georgia Institute of Technology

\title{
Introduction
}

In Atlanta, as in other growing regional centers, offices are increasingly locating outside of the Central Business District (CBD). 1 This phenomenon affects the character and function of the $C B D$, as well as the wider urban frame. In this paper, we propose to investigate the phenomenon of office location. More explicitly, we seek to analyze the factors leading to the decentralization of offices in the Atlanta area.

This analysis begins with an evaluation of the development and importance of office activities, both generally and in the case of Atlanta. Then we examine location theory in relation to the phenomenon under study. Finally, we present the results of a local survey to analyze the important components of the location decisions of a sample of firms presently situated outside of Atlanta's CBD. In this empirical part of the study, we investigate the types of companies located in the sample area, the functions these offices perform, where they were located previously, and reasons for choosing their present locations.

Our study emphasizes the need for additional research on the location of office activities. The need is particularly urgent in Atlanta. Planners, city officials, and voters alike are in need of a systematic analysis of this phenomenon in order to enable them to make more rational decisions concerning land-use and transportation (especially rapid-transit) policy. Such information could be vital to many other cities which are also in the process of enacting either rapid-transit or other costly and long-range programs. With a more complete knowledge of where offices will seek to locate and why they will do so, city planners and public officials can more effectively meet the future problems of the cities.

\section{Location Theory}

The importance of the location of office activities

Time is a relevant factor determining the geographical dispersal of economic activities. The "stages theory" of economic development divides the growth of a region into three time periods. 2 Generally, regions begin development with primary industries--agriculture, mining and other extractive operations, and fishing. In the secondary stage, regions develop and specialize in manufacturing industries. In the final stage, large service sectors must come into being to support the manufacturing industries. If the "stages theory" is an acceptable explanation of regional growth, it may further indicate which economic activities are the most significant at a particular time in a region. For an economy in the secondary stage of growth, one would expect that manufacturing activities would be the most significant, but as the region passes to the tertiary stage, one would expect the importance of office activities to supersede all others. 3

A high percentage of workers in tertiary industries in relation to the total work force exhibits evidence of a region's transition to the highest level of development. Another less obvious factor would be the volume of construction of office buildings as a percentage of total construction.

Nationally and locally, employment in service industries has been increasing. In the United States as a whole, it was 45 percent of the total labor force in 1947. By 1956, the figure had risen to 50 percent, and in 1967, it was more than 60 percent. ${ }^{4}$ In the Atlanta area, as early as 1961, the percentage of workers in tertiary industries had already surpassed 59 percent of the total work force. 5 
Construction statistics for the Atlanta area further reflect the increasing importance of the service sector. During the $1960^{\prime}$ s, office construction has exceeded the construction of manufacturing plants by approximately 100 percent. During these years, 10.6 million square feet of plant area was built, as compared to 19.1 illion square feet of office space. 6

The trend toward spatial separation of strictly production and non-production activities at plant sites is another factor evidencing the importance of office activities. In Atlanta, approximately 34 percent of the offices in the sample are either headquarters or regional offices of manufacturing companies. As technological advances continue in the fields of communications and data storage and transmission, and as these advances facilitate the continued separation of production and non-production activities, 7 we can only expect the growth of offices to accelerate in our regional centers. 7

Because of the increasing importance of office activities, the location of these activities within metropolitan areas also becomes increasingly important. As office activities grow in number and significance, as dollars of investment in office buildings rise sharply, and as the impact of their location outside of the CBD becomes more widespread and intense, the necessity for understanding this decentralization phenomenon becomes more urgent.

Atlanta currently has seventeen suburban office parks either completed, partially completed, or on the drawing boards. Together, these offices represent an investment of over $\$ 350$ million and about 12 million square feet of office space. 8 Almost three square feet of suburban office space was added for every one square foot of downtown office space between 1945 and 1964.9 The continuation of this trend constitutes a threat to the CBD.

\section{Relation to classical theory}

In the past, as regions evolved to higher stages of development, explanations of the location of dominant economic activities were forthcoming. But to date no research has expounded a complete theory of the location of office activities.

In 1826 , when Germany was in the primary stage of development, Johann Heinrich von Thlinen, one of the pioneers in location theory, examined the way in which farming districts are affected by their distance from a punctiform market. According to his thesis, a ring pattern of specialized crop cultivation will result as farmers try to maximize rents (the difference between price paid at the market and transportation costs). As the distance from the market increases, the land will progressively be given up to products that are cheap to transport in relation to their market value. 10 Thus, the major concern of Thünen is how rent serves to determine the use of agricultural land.

In the early twentieth century Alfred Weber developed the theory of industrial location, "not only because they (industrial location decisfons) are neglected, but because they are so far-reaching in fact."11 Thus Weber attempted to explain the location of industries as Germany passed into the secondary stage of development.

In contrast to von Thünen, Weber does not ask to what use a parcel of 1 and can be put. Rather he asks: "What causes a given industry to move from one location to another?"12 His theory of location seeks to depict general economic laws governing the movement of industries. After defining labor and transport costs as the primary determinants governing these movements, Weber sets forth these two rules:

1) The location of manufacturing industries is determined (labor costs assumed to be constant) by the ratio between the weight of localized material and the weight of the products.

2) When labor costs are allowed to vary, an industry deviates from its transport location in proportion to the size of its labor coefficient (cost of 1 abor per ton/total welght of all goods).13 
Further, Weber defines the indirect facrors of location to be agglomerative and deglomerative forces. He classifies these as subjective factors and concludes that they are difficult to measure and, thus, hard to quantify.

To the theory of Industrial location, August Lo'sch, another pioneer in location theory, has added the concept of total orlentation. According to his analysis, the location of an industry is a continuation of the profit-maximization assumption. When employed to compare alternative sites, this method declares that the preferred location is the one associated with the greatest profits (revenue less processing and transport costs). 14

The three explanations of location discussed above emphasize differing factors as determinants of locational decisions. In the case of agriculture, rent is the dominant variable. Transport costs are stressed by Weber, whereas Lösch includes revenue as an important distance variable. The significant point to note is that no matter which of the variables is stressed, each theory of location is contingent upon distance variables.

Because of the special emphases of these three classical location theories, we find them to be of limited value in explaining office locations. Additionally, because the location of offices tends to be an intra-regional phenomenon, distance variables are less relevant. In the classical theories, the principal distance variables are the costs of transporting outputs and inputs. Yet within the metropolitan area the significant inputs (people, information, equipment, and supplies) and outputs (information) show negligible transport cost differentials. One could argue that although companies do not directly pay for the transportation of their employees, they must bid up salaries to induce workers to incur the additional trave1 (time and money costs) associated with CBD 1ocations. A cursory investigation indicates, however, that intra-city differentials in salaries between suburban and CBD companies are of smal1 magnitude, and the differences that do exist are primarily in terms of labor quality. When we exclude labor transportation costs--and this is a significant exclusion when translated to mean labor quality--we must conclude that input and output transportation costs, the crux of agricultural and industrial location theory, are insignificant variables in expalining the location of office activities.

Because offices usually have no physical output, revenue-maximization analysis is difficult to apply. Therefore, since niether transport costs nor revenues nor any other apparent distance variables used in classical theory can be applied directly to explain the location of office activities, we must reject the classical theories as tools for analyzing this relatively new location phenomenon. An exception to this general conclusion is Weber's concept of agglomerative and deglomerative forces as indirect factors influencing industrial location decisions. This concept seems to provide the link between classical location theories and the recent literature on the decentralization phenomenon in general and office decentralization in particular.

\section{Relation to recent theory}

The theories of urban structure hypothesize and describe relationships which are important to the study of office location. Although the location of office activities is not the main subject of these theories, they are, nevertheless, helpful in analyzing the forces which determine urban land use. Studies identifying urban structures in terms of concentric rings (Ernest Burgess), 15 sector specialization (Homer Hoyt), 16 and multiple nuclei (Chauncy Harris) 17 have provided us with descriptions of the historical growth patterns of American cities.

Ernest Burgess describes city structure in terms of five concentric rings (zones) which start in the center of the city and move outward. He names these rings (from the center to the periphery) the central business district, the zone of transition, the zone of independent workingmen's homes, the zone of better residences, and the commuters' zone. This theory is a generalization which can be applied to most American cities. 
Hoyt's theory considers the effect of lines of transportation upon city structure. In his sector theory, he hypothesizes that simtlar land uses develop and extend along the lines of transportation within the city. These sectors, like those of Burgess, originate in the center and radiate out toward the periphery of the city.

Some cities have numerous centers, rather than just one. This structure is what Harris describes in the multiple-nuclei theory. He hypothesizes that this multinucleation occurs in cities in which speclalized districts evolve. One example of a city's development around two separate nuclei is Metropolitan London, where Westminster and "The City" originated separately. Each grew surrounded by open space, one becoming a center of finance and commerce while the other was becoming a political center.

Although a city's structure will rarely conform precisely to one of these theories, it can usually be described by a combination of them. Whereas the Central Business District is described in each of these theories, none makes explicit mention of an "office center" or even of the location of offices.

As early as 1927, R. M. Haig delineated the essentials for understanding urban morphology. He hypothesized that activities within cities locate to overcome "the friction of space." The costs of overcoming this "friction" are transportation charges and rents, and the preferred location would be the one which minimizes the sum of these costs. 19 This theory can be applied to the location of offices if transportation costs are viewed differently, i.e., as the cost paid by employees (including executives) in terms of time and dollars spent traveling to and from work. We have previously observed that wage-rate differentials within the city are minimal and that the differentials which do accrue are in terms of the quality (and possibly available quantity) of employees. We shall attempt to utilize Haig's concept of the "friction of space" and test whether companies locate not only to capitalize on lower rents, but also to reduce the time and money costs of the employees' daily travel to and from work.

\section{Decentralization as a location phenomenon}

Whereas the theory of location of economic activity between and among cities is well developed, the theory of decentralization of economic activity within an urban area is in an embryonic stage. The automobile is recognized as the primary force precipitating recent decentralization. Prior to the advent of the automobile, residences were located near train, trolley, or subway tracks, and people were generally found living close to the center of town. 20 The cities were centers where ships and/or railroads came in and out, where travelers congregated, and where news was dispensed. The city furnished the only concentrated supply of educated people who could satisfy the demands for clerical workers.21 Financlal institutions were the first to locate. office activities in the central cities, which soon became the prestigious location for all types of office activities.

Once the automobile became the dominant form of transportation, many workers found that they could enjoy the fruits of the city while residing in outlying areas. Since development was no longer limited to areas with access to public transportation, the boundaries of cities gradually expanded as people began moving to the suburbs. Commercial establishments followed residential development into suburban areas. Once this trend commenced, other economic activities, including office activities, began looking to the suburbs.

In addition to the automobile and the resultant decentralization of residences and commercial activities, other more recent factors have influenced office decentralization. The first of these stems from the increased demand for office space in the regional centers (the cities which are experiencing the most office decentralization). 22 This increased demand has resulted in an increased price for offices in the CBD. In turn, higher rents for office space have caused a boom in office construction. Although part of this boom is evidenced by an increase in the number of office buildings in the CBD, higher rents have also caused an office-building boom in non-CBD areas--espectally the suburbs. 
The congestion of our central citles is another factor leading to decentralization. As the populations of these cities grow, roads and expressways become clogged beyond capacity, public transit breaks down, and the price of parking often becomes prohibitive. The suburbs are not only closer to the homes of the workers, but they also lack most of these problems of congestion. The increased prices for parking and the congestion in the central cities are what Weber would call deglomerative forces.

The suburban office park is another crucial catalyst in the movement of offices to the suburbs. Office parks are attracting many companies searching for an area that is aesthetically pleasing, where parking is inexpensive, where time and distance to work are greatly shortened, where there is a lack of congestion, and where many of the agglomerative forces once exclusively obtainable downtown are now provided. Office parks often contain restaurants, shopping malls, barber shops, and other facilities and/or services which the office employees desire. 23

Among the factors facilitating the separation of more companies from the $\mathrm{CBD}$, one of the most important is improvements, both existent and anticipated, in communications technology. The telephone industry provides an excellent example of the effect of this factor on office location. New innovations in dialing techniques haye permitted the physical dispersion of the once centralized operator facilities. 24 Related to communications improvements are technological adpancements in data storage and transmission. Thus, many New York banks are moving their accounting facilities to the suburbs, and Eastern Airlines is moving its reservations offices to the suburbs in both New York and Atlanta. 25 Among other innovations facilitating dispersions of this type are remote terminals, long-distance xerography, data phones, and the lowering of telephone rates through such special business arrangements as wide-area telephone service (WATS).26

Although there are factors pushing companies out of the CBD and other factors drawing companies to the suburbs, it appears that certain types of companies or offices will remian tied to the CBD, those companies which must maximize their contact with and availability to the entire metropolitan area. 27 It is also reasonable to expect that many of the institutions which serve these companies will remain in the core. Thus, there are limits on the number of financial and legal firms that can be expected to participate in decentralization.

\section{The Empirical Results}

The study area

Figure 1 provides an illustration of the area under study. The compact nature of this sample area and its high proportionof office activities suggested that it would be an ideal workshop for studying the decentralization phenomenon. Additionally, it contains attributes which we initially hypothesized from classical theory and popular literature on office parks as being of importance to the location decistons of firms:

1) It is bounded on all sides by interstate highways.

2) Both its family incomes and educational levels rank well above average (See Figures 2 and 3.) 28

3) The construction of office facilities within this area has been heavy, comprising at least 40 percent of the office construction in Atlanta between 1960 and 1967.

4.) It has become a growth area of Atlanta, and contains several major shopping districts.

\section{Design of the study}

The first phase of the study included personal interviews with executives of offices in one of Atlanta's most successful office parks. We conducted these interviews for the purpose of learning what factors in the location decision are most significant to the men who make or influence such decisions. In order that the interviewer would not bias the executives in any way, these interviews were left open-ended. The executives were asked: "What were the most important 


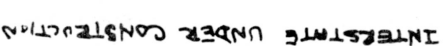

wəlsts glusaanI hanis to $\forall \Rightarrow y$

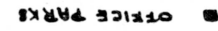

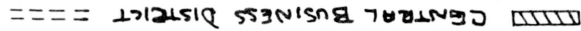

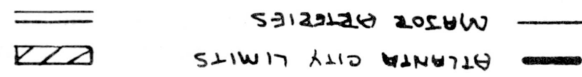

\section{LonIS $10 \quad \forall \exists y \forall-$ I $\exists y n g l y$}

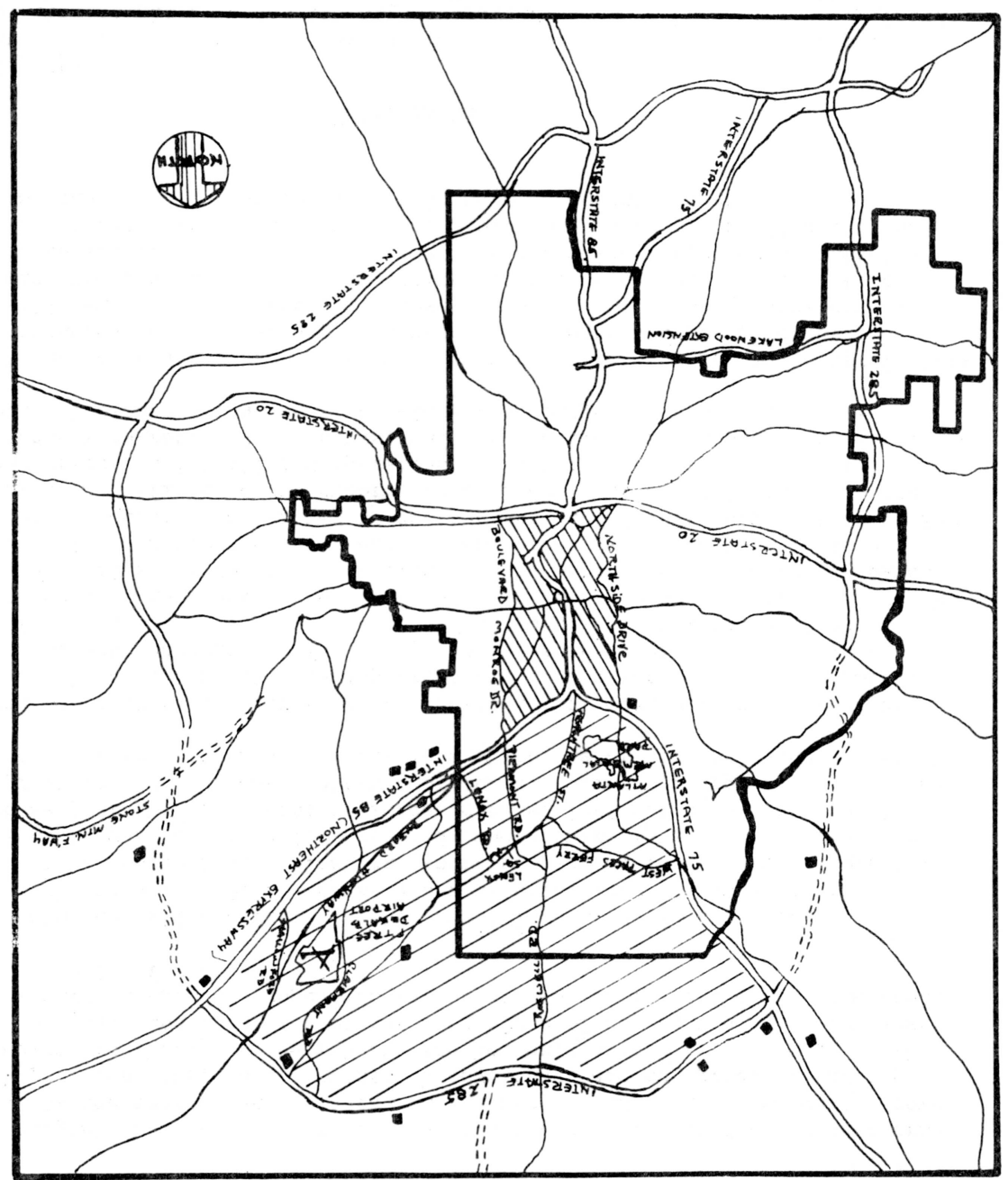




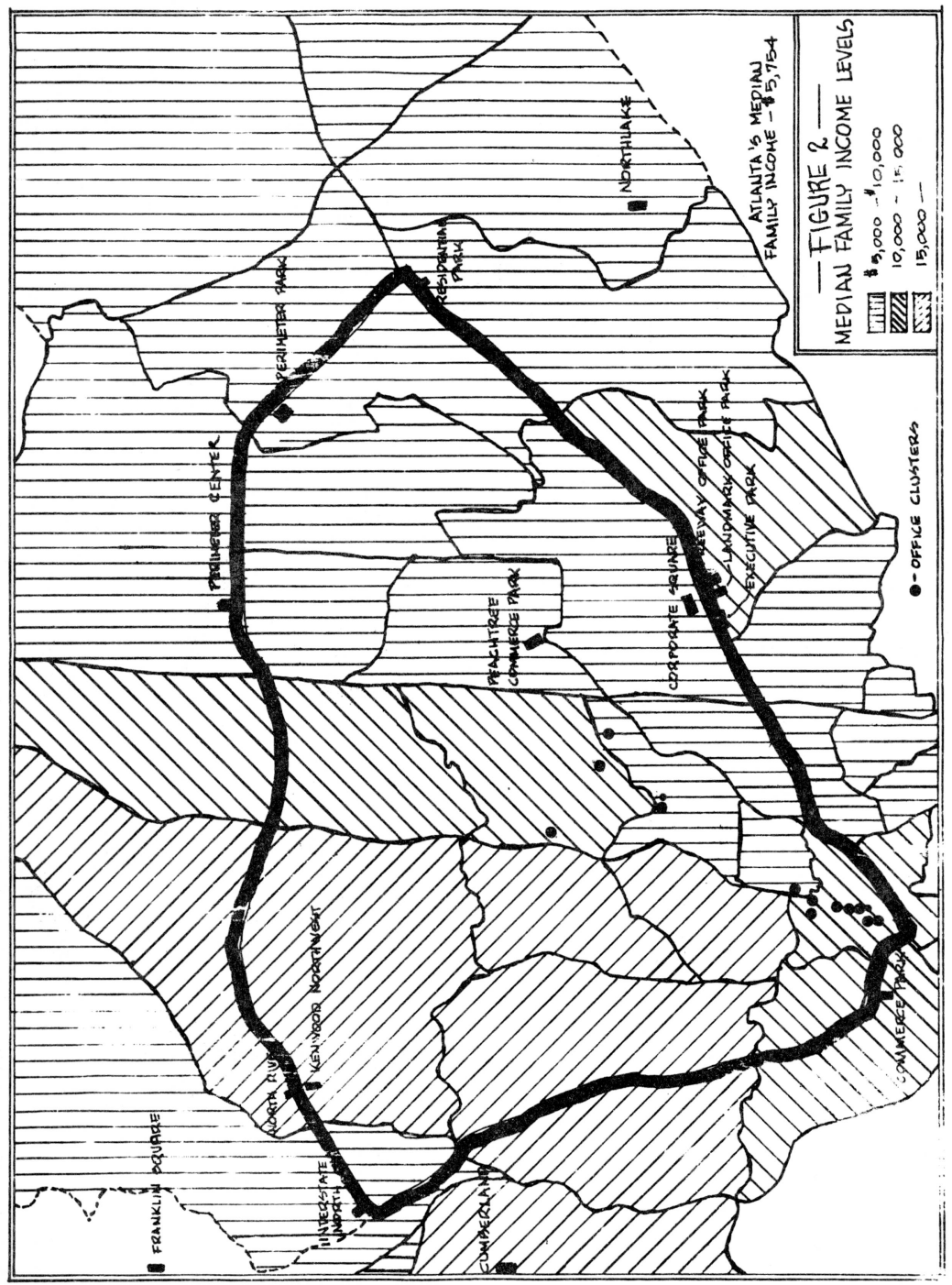




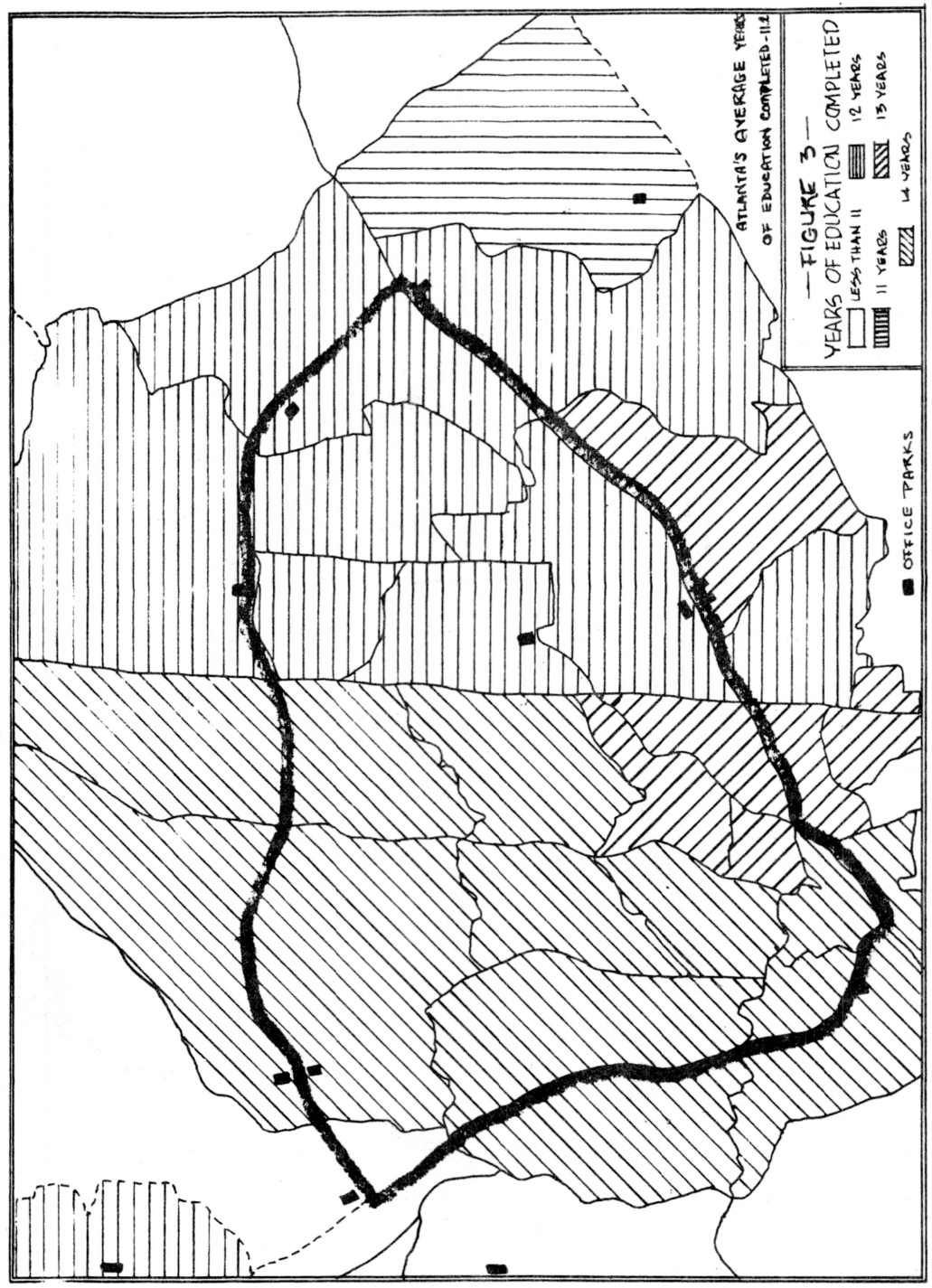


factors which caused you to decide to locate in this area?" From these interviews we constructed questionnaires. We tested the questionnaire in another area, and then made certain improvements in wording. Through the questionnaire, we collected information on the types of offices located in the sample area, the functions these offices perform, their prevtous locations, and the reasons for choosing their present locations.

We mailed the questionnaire to the highest executive in 900 offices randomly selected from office buildings and office parks in the sample area, because we felt that even if the executive had not participated in the office-location decision, he would nevertheless know the reasons for the decision better. than anyone else. This method assured us informed sources as well as an acceptable number of returned questionnaires.

The most distinct limitation of such a survey is the inevitable tradeoff between a thorough examination of the problem and an acceptable sample of respondents. We felt it necessary to make the questionnaire short and mainly closeended in order to maximize the number of returns, yet it must be acknowledged that this decision could have biased the results. It is also possible that the questionnaires were not completed by the destred respondents. We trust, however, that the large sample size will minimize the errors.

We have limited our empirical study to an investigation of the following five questions:

1) What types of companies are locating in the study area?

2) What functions do these offices perform?

3) How do they view the quantity and quality of their new labor market in contrast to their previous one?

4) Where were they located previously?

5) Why did they choose their present location?

Companies located in the study area

As can be seen in Table 1, we first surveyed the size of these suburban offices, measured according to three characteristics: number of clerical workers, number of managerial workers, and number of square feet. We have classified 67 percent of the offices as small. These offices usually include fewer than 5 clerical workers, 1 managerial worker, and less than 1,000 square feet. Those classified as medium-sized--approximately 27 percent of the offices surveyed-usually had 6 to 15 clerical workers, 2 to 10 managerial workers, and 1,000 to 19,999 square feet. We classified an additional 7 percent of the offices as large, having more than 30 clerical workers, more than 10 managerial workers, and more than 20,000 square feet.

In addition to size, we also surveyed the types of industries located in the sample. Table 2 indicates the frequency with which various industrial classifications are represented in the sample.

Functions of offices in the study area

We attempted to describe the functions of the offices in the study area in two ways. First, we determined what types of offices we were studying, i.e., main headquarters, sales offices, the only office of the firm, etc. We then defined the geographic scope of operations of the offices in order to determine whether they were national, regional, statewide, or local. This information is presented in Tables 3 and 4 .

We found that 50 percent of the offices classified themselves as sales offices and that the next most frequent group (18 percent) is main headquarters. Those which served as the only office of the firm comprise 16 percent of the sample. Although another 16 percent could not be included in these classifications, their functions allowed no meaningful fourth classification. Although half of the offices, regardless of size, are sales offices, a significant portion of the large 
TABLE 1

SIZE OF OFFICES

Classification of offices by: number of clerical workers, managerial workers, and square feet of office space

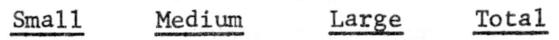

Clerica1 Workers

$\begin{array}{lcccc}0-5 & 98.1 \% & 40.0 \% & 0.0 \% & 77 \% \\ 6-15 & 1.6 & 44.2 & 6.5 & 13 \\ 16-30 & 0.3 & 12.5 & 19.4 & 5 \\ \text { more } & 0.0 & 3.3 & 74.2 & 5\end{array}$

Manageria1 Workers

1

$2-3$

$4-10$

more

Square Feet

$0-999$
$1000-9,999$
$10,000-19,999$
more

Totals

more
56.9

5.0

0.0

41

40.6

31.7

5.5 34

2.5

60.8

38.8

20

0.0

2.5

55.8

5

70.9

0.8

0.0

48

29.1

92.5

8.7

44

0.0

6.7

55.8

5

0.0

0.0

35.5

3

$67 \%$

$27 \%$

$7 \%$

$100 \%$ 
TABLE 2

TYPES OF INDUSTRIES

Industry

Number of

Manufacturing:

Food and kindred products 9

Paper and allied products 3

Printing and publishing 6

Chemicals 7

Rubber and plastics 4

Primary metals 9

Machinery 7

Electrical machinery 4

Transportation equipment 5

Other 65

$\begin{array}{ll}\text { Insurance Carriers and Agents } & 73\end{array}$

$\begin{array}{ll}\text { Miscellaneous Services } & 27\end{array}$

$\begin{array}{ll}\text { Real Estate } & 14\end{array}$

Miscellaneous Business Services 13

$\begin{array}{ll}\text { Management and Consulting Services } & 10\end{array}$

Credit Agencies other than Banks 8

General Contractors 7

Oil Companies 5

Wholesale Trade 3

Tota1 279 
TABLE 3

FUNCTIONS OF OFFICES

Type of Office*

\begin{tabular}{|c|c|c|c|c|}
\hline & Sma11 & Medium & Large & Totals \\
\hline Headquarters & $16 \%$ & $22 \%$ & $23 \%$ & $18 \%$ \\
\hline Sales Office & 53 & 43 & 39 & 50 \\
\hline Only office & 20 & 10 & 7 & 16 \\
\hline
\end{tabular}

TABLE 4

SCOPE OF OPERATIONS OF OFFICES

Type of Office

Nationwide

Regional

Georgia

Some of Georgia

Local
Size of Office

\begin{tabular}{|c|c|c|c|}
\hline Small & Medium & Large & Totals \\
\hline $7 \%$ & $13 \%$ & $13 \%$ & $9 \%$ \\
\hline 64 & 68 & 65 & 65 \\
\hline 14 & 12 & 10 & 13 \\
\hline 3 & 3 & 7 & 3 \\
\hline 12 & 4 & 5 & 10 \\
\hline
\end{tabular}


and medium-sized offices are main headquarters. For the smaller offices, the "only office" outranked main headquarters.

In terms of the area they serve, most of the respondents (65 percent) described their offices as regional. Whereas 17 percent of the executives specified their area of operations as limited to Georgia or to part of Georgia, nearly 9 percent described their range as local. A corresponding 9 percent considered their operations to be nationwide.

Although most of the small-, medium-, and large-sized offices were regional, a significant minority of the respondents from both the medium- and large-sized offices described their activities as nationwide. A corresponding portion of the executives of the smaller offices classified their operations as statewide in scope.

\section{Previous locations of companies in the study area}

The most frequent previous location of companies in the sample was Atlanta's Central Business District. Almost 34 percent of the companies fall into this category. Another 23 percent came from Northeast Atlanta and 11 percent from Northwest Atlanta, yet less than 3 percent of the offices had moved from South Atlanta. A substantial number of offices had not been located in Atlanta before: 15 percent had been located out of the city, and 14 percent were new companies. Table 5 presents a listing of the previous locations of the offices surveyed.

\section{Executives' opinions of the labor force in the study area}

Table 6 is a compilation of executives' opinions on the availability and quality of the labor force in their present vis-a-vis their former locations. When asked about their ability to attract clerical help to the two sites, 57.8 percent of the executives stated that it had improved in the new location, 1.5 percent declared that it was worse, and 40.7 percent said that it was the same. In the main, those companies which reported an improved ability to attract clerical workers were the larger offices, the main headquarters, and those previously located in Southeast Atlanta.

When asked the same question in regard to their ability to attract managerial workers, 45.3 percent of the respondents reported improvement, 54.7 percent rated the situation unchanged, and none believed that it had deteriorated. On the whole, those companies which reported an enhanced ability to attract managerial workers were the larger offices, the companies which had only one office, and those offices previously. located in Southeast Atlanta.

Some 30.6 percent of the companies' officials declared that the quality of their clerical workers had improved in their new location, whereas 66.8 percent felt that it had remained unchanged. Only 1.7 percent reported a decline in quality. The companies most frequently reporting an improvement in the quality of clerical workers were those with larger offices, those that are main headquarters, or those previously located in Southwest Atlanta.

When asked about the quality of their managerial workers, 21.6 percent of the executives agreed that it was improved, 78.2 percent stipulated that it had remained the same, and less than 1 percent felt that it had worsened. Large offices, main headquarters, and those offices previously located in Southeast Atlanta most frequently reported an improvement.

\section{Reasons for location}

Each executive was asked to rank on a scale from 1 through 5, five of the eleven reasons given on the questionnaire for choosing the present location of his office. Other reasons could be added and ranked as well. For the rankings from 1 through 5, we assigned corresponding weights of 5 through 1--e.g., a rank of " 1 " received five points, and " 5 " one point. Table 7 presents the eleven reasons (in order of rank) and the percentage of the total votes given to each.

As categorized by size of office, nature of office, and previous location, 


\section{TABLE 5}

PREVIOUS LOCATIONS OF OFFICES

Previous Location

Central Business District

Southwest

Southeast

Northwest

Northeast

Cobb County

Sandy Springs

Out of the City

New Companies

\section{Percentage of Companies}

34.0

0.8

1.8

11.0

23.0

0.2

0.2

15.0

14.0 
TABLE 6

AVAILABILITY AND QUALITY OF LABOR FORCE

\begin{tabular}{|c|c|c|c|c|c|c|c|c|c|c|c|c|c|c|c|c|c|c|}
\hline & \multicolumn{3}{|c|}{ Size } & \multicolumn{4}{|c|}{ Nature of office } & \multicolumn{9}{|c|}{ Previous Location } & \multirow[t]{2}{*}{ Total } \\
\hline & & Smal1 & Mediur & Large & Headq. & Sales & On $1 \mathrm{y}$ & Other & $\mathrm{CBD}$ & SW & SE & NW & $\mathrm{NE}$ & Cobb & SS & $\begin{array}{l}\text { Out o } \\
\text { State }\end{array}$ & New & \\
\hline \multirow{3}{*}{$\begin{array}{l}\text { Ability to } \\
\text { attract } \\
\text { clerical } \\
\text { workers }\end{array}$} & Better & 58.8 & 50.0 & 77.4 & 64.2 & 55.3 & 60.5 & 55.6 & 68.6 & 66.7 & 85.7 & 48.1 & 39.1 & 100 & 100 & 58.6 & 63.6 & 57.8 \\
\hline & Worse & 1.3 & 1.7 & 3.2 & 1.2 & 1.7 & 1.3 & 1.3 & 0 & 0 & 0 & 3.8 & 2.8 & 0 & 0 & 1.4 & 1.5 & 1.5 \\
\hline & Same & 40.0 & 48.3 & 19.4 & 34.6 & 43.0 & 38.2 & 43.1 & 31.4 & 33.3 & 14.3 & 48.1 & 57.4 & 0 & 0 & 40.0 & 34.9 & 40.7 \\
\hline \multirow{3}{*}{$\begin{array}{l}\text { Ability to } \\
\text { attract } \\
\text { managers }\end{array}$} & Better & 49.5 & 31.7 & 54.8 & 55.6 & 25.5 & 56.6 & 36.1 & 49.4 & 66.7 & 71.4 & 38.5 & 31.5 & 100 & 100 & 42.9 & 60.6 & 45.3 \\
\hline & Worse & 0 & 0 & 0 & 0 & 0 & 0 & 0 & 0 & 0 & 0 & 0 & 0 & 0 & 0 & 0 & 0 & 0 \\
\hline & Same & 50.5 & 68.3 & 45.2 & 44.4 & 74.5 & 43.4 & 63.9 & 50.6 & 33.3 & 28.6 & 61.5 & 68.5 & 0 & 0 & 57.1 & 39.4 & 54.7 \\
\hline \multirow{3}{*}{$\begin{array}{l}\text { Quality of } \\
\text { clerical } \\
\text { workers }\end{array}$} & Better & 32.0 & 27.5 & 51.6 & 37.0 & 29.8 & 29.0 & 33.4 & 44.2 & 66.7 & 57.1 & 32.7 & 24.1 & 100 & 100 & 21.4 & 15.2 & 30.6 \\
\hline & Worse & 1.3 & 3.4 & 0 & 3.7 & 0.4 & 3.9 & 1.3 & .6 & 0 & 0 & 1.4 & 4.6 & 0 & 0 & 1.4 & 0 & 1.7 \\
\hline & Same & 66.7 & 69.1 & 48.4 & 59.3 & 70.0 & 67.1 & 65.3 & 55.2 & 33.3 & 42.9 & 65.9 & 71.3 & 0 & 0 & 77.2 & 84.8 & 66.8 \\
\hline \multirow{3}{*}{$\begin{array}{l}\text { Quality of } \\
\text { managers }\end{array}$} & etter & 21.4 & 18.3 & 35.5 & 32.1 & 18.7 & 17.1 & 23.6 & 30.8 & 33.3 & 57.1 & 30.8 & 15.7 & 100 & 100 & 11.4 & 6.1 & 21.6 \\
\hline & Worse & 0.3 & 0 & 0 & 0 & 0 & 1.3 & 0 & 0 & 0 & 0 & 0 & 0.9 & 0 & 0 & 0 & 0 & 0.2 \\
\hline & Same & 78.3 & 81.7 & 64.5 & 67.9 & 81.3 & 81.6 & 76.4 & 69.2 & 66.7 & 42.9 & 69.2 & 83.4 & 0 & 0 & 88.6 & 93.9 & 78.2 \\
\hline
\end{tabular}


TABLE 7

RANKINGS OF LOCATIONAL FACTORS

\section{Factors}

1. Less traffic congestion

2. Nicer, newer offices with better facilities

3. More space

4. Better access to expressways

5. Better parking

6. Prestige location

7. Proximity to managers' homes

8. Proximity to office forces' homes

9. Cheaper to operate here

10. More convenient to clients

11. A growing area of town
Percent of Total Rankings

$18.9 \%$

15.7

11.6

10.2

10.1

8.1

6.9

5.8

4.4

4.4

3.9 
Table 8 lists the percentage of votes given to each location reason. Table 9 ranks the reasons by each of these categories.

An analysis of each location reason is useful in determining whether any of these reasons is particularly significant (or insignificant) for any of the categories of offices. The desire for "nicer, newer offices with better facilities" is an important consideration both for large offices and for those previously located in Northeast Atlanta, in Cobb County, and in Sandy Springs. Yet it seems insignificant for those companies which have not been located in Atlanta before. The desire to reduce or eliminate traffic congestion, though important to all the companies, was not particularly significant for those previously located outside the CBD in Northeast Atlanta, in Sandy Springs, in Cobb County, and in Southeast Atlanta.

For those companies previously located either in Southwest or in Southeast Atlanta, the desire to be close to the managers' homes seems important. For the larger offices, it seems insignificant probably because the location decisions are made by officials well removed from the local scene. For all of the offices, proximity to the homes of the office force seems unimportant with the possible exception of the medium-sized offices. That it is a growing area of town seems to have motivated those offices previously located in Cobb County. Except possibly for the new companies, none seems to have been particularly motivated by the conviction that it would be cheaper to operate in the area.

The section's reputation as a "prestige location" weighed heavily in the location decisions of offices from Southwest Atlanta (an area lacking prestige), whereas the medium- and large-sized offices, as well as those previously located in Northeast Atlanta and Cobb County, felt the desire for more space to be of greater concern. The desire for larger facilities was of little importance for new companies or for those previously located outside Atlanta.

Those companies that had not had offices in Atlanta previously seemed to feel that access to expressways was important, whereas the larger offices did not rate this as a very significant factor. Although better parking facilities influenced the decisions of most of the companies, those previously located in Southeast and Southwest Atlanta seemed the least motivated by a desire for these facilities. The companies previously located in Southeast Atlanta and Cobb County indicated that their new location made them more convenient to their clients.

\section{Conclusions}

We have ascertained in some detail the nature and causative factors of office decentralization in a limited geographical location. Although Atlanta provides the only data for our empirical findings, we believe that these findings can be generalized to other regional centers which, to a lesser or greater extent, are also undergoing office decentralization. It was not our purpose in this paper to provide a theory of office decentralization. We do hope, however, that we have developed part of an empirical base on which a theory explaining this phenomenon can be built.

As a result of our research, we can verify the allegation that the decentralization phenomenon does exist. That 71 percent of the companies in the sample had previous locations in the city provides evidence that relocation is a widespread phenomenon in Atlanta. That some 34 percent of the offices were previously located in the Central Business District confirms the decentralization hypothesis.

In addition, we have learned some bastc facts about the offices in the study area. Generally, they are small. Most are sales offices whose scope of operations usually extends regionally (over more than one state). Except for branch banks and savings and loan associations, we see no substantial dispersion of financial activities. In addition, we see little dispersion of the offices of manufacturing and professional service industries which rely on high volumes of consumer traffic and serve the entire metropolitan area. The offices which have been most subject 
TABLE 8

LOCATIONAL FACTORS BY SIZE, FUNCTION, AND PREVIOUS LOCATION

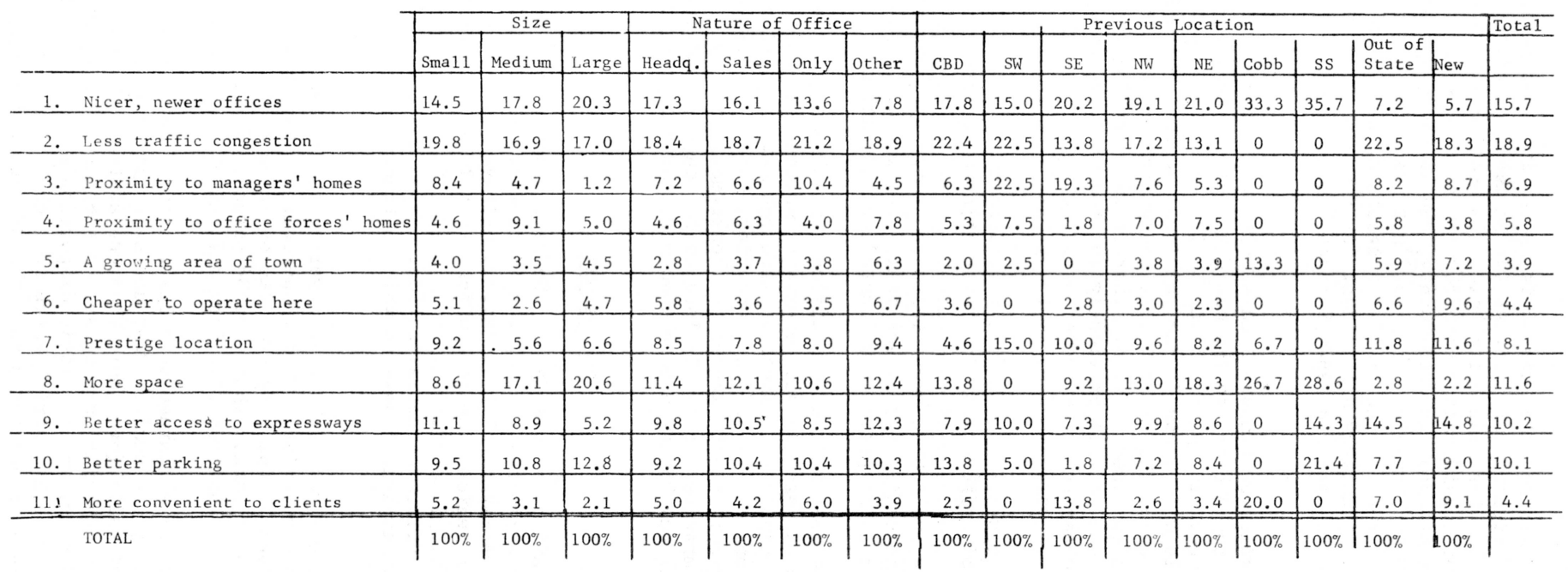


TABLE 9

RANKING OF LOCATIONAL FACTORS BY SIZE, FUNCTION,

AND PREVIOUS LOCATION OF OFFICES

Rankings by Size

\section{$\underline{\text { Sma11 }}$}

Less traffic congestion

Nicer, newer offices

Better access to expressways

Better parking

Prestige location

\section{Main Headquarters}

Less traffic congestion Nicer, newer offices More space

Better access to expressways

Better parking

\section{$\underline{\text { CBD }}$}

Less traffic congestion Nicer, newer officer More space

Better parking

Better access to expressways

NW

Nicer, newer offices Less traffic congestion

More space

Better access to

expressways

Prestige location

\section{Sandy Springs}

Nicer, newer offices

More space

Better parking

Better access to

expressways

\section{Medium}

Nicer, Newer offices

More space

Less traffic congestion

Better parking

Proximity to office

forces' homes

\section{Rankings by Nature of Office}

\section{Sales Office}

Less traffic congestion

Nicer, newer offices

More space

Better parking

Better access to expressways

Rankings by Previous Locations

SW

Less traffic congestion Proximity to managers' homes Nicer, newer offices Prestige location

Better access to expressways

\section{NE}

Nicer, newer offices

More space

Less traffic congestion

Better access to expressways

Better parking

\section{Out of Town}

Less traffic congestion

Better access to expressways

Prestige location

Close to managers' homes

Bèter parking

\section{Large}

More space

Nicer, newer offices

Less traffic congestion

Better parking

Prestige location

\section{Only Office}

Less traffic congestion

Nicer, newer offices

More space

Better parking

Proximity to managers' homes

\section{SE}

Nicer, newer offices

Proximity to managers' homes

Less traffic congestion

More convenient to clients

Prestige location

Cobb Co.

Nicer, newer offices

More space

More convenient to clients

A growing area of town

Prestige location

\section{New Companies}

Less traffic congestion Better access to expressways

Prestige location

Chepare to operate here

More convenient to clients 
to decentralization have been either those representing service industries with no physical output or those which engage in non-production activities separate from the production site.

Moreover, the study substantiates the idea that certain deglomerative forces not only exist in the Central Business District but also give rise to the decentralization of those offices which can separate from the CBD. In the ranking of location reasons in Table 7, we see that traffic and parking are the main deglomerative forces that push offices from the urban core. In addition, we believe that the desire for space motivates offices to leave the $\mathrm{CBD}$ and to respond to the differences in real cost between $C B D$ and suburban locations. Thus the high cost of office space is becoming another deglomerative force.

In addition to the deglomerative forces are the agglomerative ones: Just as offices were initially drawn to the CBD, similar forces are now causing them to form clusters and to locate in suburban office parks. It should be remembered that the availability of "nicer, newer offices with better facilities" was the second most frequent reason for location given by the executives queried. Thus, one of the most obvious of the deglomerative forces is the amenities which developers seek to offer in office parks--new, beautiful buildings and an attractive, controlled environment.

In light of the fact that almost no executives queried expressed disapproval of the labor force in their new location and that a significant percentage felt the labor force to be not only equal to but better than that in other locations, it is not surprising that three of the first five reasons for location--less traffic congestion, better parking, and better access to expressways--are mainly employee-centered. Since most of the offices are of the type which require little face-to-face customer contact, even proximity to managers' and the present office forces' homes ranked higher than convenience to clients, a poor tenth out of the eleven reasons on the questionnaire. This high frequency of responses to employee-centered reasons for location adds weight to the contention that offices locate close to what they feel to be a superior labor market, in an attempt to reduce the "friction of space."

The final aspect of office dispersion that we considered involved the direction it has taken. In Atlanta the movement of offices has been northward, and it promises to continue further in this direction. Of the 464 respondents, only two have moved toward the $\mathrm{CBD}$ in finding their present location; only five desire to relocate again in the direction of the CBD. On the other hand, ninety executives--almost 20 percent of the respondents--indicate that they desire to relocate their offices even further north, away from the CBD. The reasons previously given--less traffic congestion, desire for newer offices with better facilities, more space, access to expressways, etc.--are the same ones given for this desire for further relocation. 
FOOTNOTES

${ }^{*}$ The authors are Associate Professor of Economics and Graduate Research Assistants in the School of Industrial Management.

This research is part of a program supported by the Office of Economic Research, Economic Development Administraton, U. S. Department of Commerce (OER-163-G-67-13) and the School of Industrial Management, Georgia Institute of Technology.

$1_{\text {See }}$ Figure 1.

2 For a more complete analysis of the "stages theory" see Douglas North, "Location Theory and Regional Economic Growth," Journa1 of Political Economy 63 (June 1955): 243-258.

${ }^{3}$ This results because the major activities of tertiary industries generally take place in offices or office buildings. As the tertiary age continues, one would expect the number and importance of office activities to grow.

4"The Service Economy Grows - But Does It?" Business Week, 15 February 1969, pp. 126-130.

${ }^{5}$ This figure is derived from figures in "1961 Employment Distribution," prepared for the Atlanta Regional Metropolitan Planning Commission by consultants Hammer and Company. "Service employment" includes all workers engaged in the following activities: retail sales of service industries, office services, recreational services, transportation, communications, utilities, and others (finance and government).

${ }^{6}$ Altanta Chamber of Commerce, Atlanta: A Research Report - Major Construction in the Sixties, one of a series of reports prepared by the Research Department of the Atlanta Chamber of Commerce. The report covers the years 1960-1968 and includes only constructions which amount to more than 20,000 square feet.

7 Fred A. Tarpley, Jr., "Technology, Labor Markets, and Location," Southeastern Regional Science Association Papers (Knoxville: University of Tennessee, 1968), p. 150 .

8 Figures from an unpublished compilation on office parks by the Atlanta Chamber of Commerce.

${ }^{9}$ From a speech given to the Atlanta Jaycees on $7 \mathrm{Ju} 1 \mathrm{y} 1967$ by Mr. Thomas Cousins of Cousins, Inc., an Atlanta development company.

10Johann Heinrich von Thinen, The Isolated State, trans, by Carla M. Wartenberg (New York: Pergamon Press, 1966), p. 12.

${ }^{11}$ Alfred Weber, The Theory of the Location of Industries, trans. by Carl Friedrich (Chicago and London: University of Chicago Press, 1929), p. 6.

${ }^{12}$ Ibid., p. xxii.

$13^{\text {Ibid. , p. } 123 .}$

${ }^{14}$ August Lösch, The Economics of Location (New York: John Wiley \& Sons, Inc., 1967), p. 27 .

15Ernest Burgess, "The Growth of the City," in The City, ed. by Robert E. Park, Ernest W. Burgess, and Roderick D. McKenzie (Chicago: University of Chicago Press, 1925), pp. 47-62; and Ernest W. Burgess, "Urban Areas," in 
FOOTNOTES----Continued

Chicago, An Experiment in Social Science Research, ed. by T. V. Smith and Leonard D. White (Chicago: University of Chicago Press, 1929), pp. 113-138.

16 Homer Hoyt, "City Growth and Mortgage Risk," Insured Mortgage Portfolio 1, Nos. 6-10 (December 1936-April 1937), passim; and Homer Hoyt, The Structure and Growth of Residential Neighborhoods in American Cities, for the U. S. Federal Housing Administration (Washington: Government Printing Office, 1939).

17 Chauncy D. Harris, "Suburbs," American Journal of Sociology 49, No. 1 (July 1943): 6

${ }^{18}$ Chauncy D. Harris and Edward L. U1lman, "The Nature of Cities," in Cities and Society, ed. Paul K. Hatt and Albert J. Reuss, Jr. (Glencoe, I11.: The Free Press, 1957), p. 244.

${ }^{19}$ R. M. Haig, Major Economic Factors in Metropolitan Growth and Arrangement (New York: Regional Plan of New York and Its Environs, 1927), pp. 38-39.

${ }^{20}$ Richard L. Nelson, The Selection of Retail Locations (New York: F. W. Dodge Corporation, 1958), p. 9.

${ }^{21}$ Raymond Vernon, The Changing Economic Function of the Central City, Supplementary Paper No. 6, Committee for Economic Development, 1959, p. 55.

${ }^{22}$ Ibid., p. 58.

${ }^{23}$ Kingdon Helie, "Planning for Suburban Office Parks," (unpublished Master's thesis, Department of City Planning, Georgia Institute of Technology, 1967), pp. 2-5.

${ }^{24}$ Tarpley, op. cit., p. 151 .

25"Wooing White Collars to Suburbia," Business Week, 8 July 1967, p. 97.

${ }^{26}$ Tarpley, op. cit., p. 156 .

27 For further discussion, see Louis $\mathrm{K}$. Loewenstein, "The Location of Urban Land Uses," Land Economics 39 (November 1963), 407-420.

${ }^{28}$ U. S. Bureau of the Census, Census of Population and Housing: 1960, Census Tract Report No. 8, pp. 14-32. 


\section{BIBLIOGRAPHY}

Alonso, William. "A Theory of the Urban Land Market," Papers and Proceedings of the Regional Science Association, 6 (1960), 149-157.

Atlanta Chamber of Commerce. Atlanta: A Research Report--Major Construction in the Sixties.

"The Beauty of Atlanta's Boom," The Atlanta Journal and Constitution Magazine, 2 April 1967.

Burgess, Ernest W. "The Growth of a City," The City. Edited by Robert E. Park, Ernest W. Burgess, and Roderick D. McKenzie. Chicago: University of Chicago Press, 1925, pp. 47-62.

, and Bogue, Donald J. Urban Sociology. Chicago: University of Chicago Press, 1964.

Dickinson, Robert E. City and Region. London: Routledge and Kegan Paul, Ltd., 1964 .

Goddard, John. "Changing Office Location Patterns Within Central London," Urban Studies 4 (November 1967): 276-285.

Haig, R. M. Major Economic Factors in Metropolitan Growth and Arrangement. New York: Regional Plan of New York and Its Environs, 1927.

Harris, Chauncy D. and Ullman, Edward L. "The Nature of Cities," Cities and Society. Edited by Paul K. Hatt and Albert J. Reuss, Jr. Glencoe, Il1.: The Free Press, 1957, pp. 237-247.

Helie, Kingdon. "Planning for Suburban Office Parks." Unpublished Master's Thesis, Department of City Planning, Georgia Institute of Technology, 1967.

Hoyt, Homer. "Recent Distortion of the Classical Models of Urban Structure," Land Economics 40 (May 1964): 199-212.

Lowenstein, Louis K. "The Location of Urban Land Uses," Land Economics 39 (November 1963): 407-420.

Lösch, August. The Economics of Location. New York: John Wiley and Sons, Inc., 1967 .

McKeever, J. Ross. The Community Builders Handbook. Washington, D. C.: The Urban Land Institute, 1968.

Murphy, J. J. "How Much Space and Where?" Office Executive 36 (October 1961): 12-16.

North, Douglas C. "Location Theory and Regional Economic Growth," Journal of Political Economy 63 (December 1955): 243-258.

"The Office Center of the World, 2000 A. D." The Office 65 (May 1967): 62-66.

"Offices are Spreading in New York's Business Area," The Office 66 (December 1967): 44 and 89 .

"The Service Economy Grows--But Dbes It?" Business Week, 15 February 1969, pp. 126-130. 
Studkey, Julien J. "Finding and Leasing Office Space," Office Executive 36 (Apri1 1961): 22-24 and 29.

Tarpley, Fred A., Jr. "Technology, Labor Markets, and Location," Southeastern Regional Science Association Papers. Knoxville: University of Tennessee, 1968, pp. 149-156.

U. S. Bureau of the Census. Census of Population and Housing: 1960. Census Tract Report No. 8.

Vernon, Raymond. The Changing Economic Function of the Central City. Supplementary Paper No. 6, Committee for Economic Development, 1959.

von Thlinen, Johann Heinrich. The Isolated State. Translated by Carla M. Wartenberg. New York: Pergamon Press, 1966.

Weber, Alfred. The Theory of the Location of Industries. Translated by Car1 Friedrich. Chicago: University of Chicago Press, 1929.

"Wooing White Collars to Suburbia," Business Week, 8 July 1967, pp. 96-98. 